\title{
Epidemiological, clinico-haematological and therapeutic studies on canine demodicosis
}

\begin{abstract}
This study was designed to investigate the prevalence, clinical examination and therapeutic management of canine demodicosis cases presented to the Teaching Veterinary Clinical complex of CSKHPKV, Palampur. A total of seventy dogs (male-fifty-five and female fifteen) having dermatitis were examined and twenty-two cases $(31.42 \%)$ were found positive for demodicosis. The prevalence of demodicosis was found higher in the dogs of $0-1$ years of age $(36.36 \%)$ than in the dogs of $1-3$ years of age $(31.81 \%)$. Infestation of Demodex was significantly $(\mathrm{p}<0.05)$ higher in male $(81.82 \%)$ than female $(18.18 \%)$ dogs. Grossly, alopecia, corrugation of skin, crusts and pruritus were found. Out of twentytwo, fifteen dogs were found affected with generalized demodicosis and haematological examination from these dogs revealed significant reduction in total erythrocyte count $\left(5.04 \pm 0.11 \times 10^{6} / \mathrm{mm}^{3}\right)$ and haemoglobin level $(10.85 \pm 0.33 \mathrm{~g} / \mathrm{dl})$. Affected dogs also showed leukocytosis $\left(15.31 \pm 1.92 \times 10^{3} / \mathrm{mm}^{3}\right)$ accompanied by neutrophilia $(71.80 \pm 0.54 \mathrm{x}$ $\left.10^{3} / \mathrm{mm}^{3}\right)$, eosinophilia $\left(2.38 \pm 0.29 \times 10^{3} / \mathrm{mm}^{3}\right)$ and lymphopenia $\left(23.60 \pm 0.65 \times 10^{3} / \mathrm{mm}^{3}\right)$. The dogs were treated with ivermectin, amitraz, antibiotic, benzyl peroxide shampoo, along with supportive therapy, and showed recovery after treatment. Out of twenty-two cases, fifteen cases responded, and their skin scrapings were found negative for Demodex spp. after three weeks of treatment. The results indicated that companion animals in and around the Palampur area are very much susceptible to Demodex spp. infestation.
\end{abstract}

Volume 7 Issue $3-2018$

\author{
Pardeep Sharma, Des Raj Wadhwa, Ajay \\ Katoch,Ankur Sharma \\ Department of Veterinary Medicine, DGCN-College of \\ Veterinary and Animal Sciences, India
}

Correspondence: Pardeep Sharma, Department of Veterinary Medicine, DGCN-College of Veterinary and Animal Sciences, CSKHPKV- Palampur, Himachal Pradesh-176062, India, Email docpradeepsharma@gmail.com

Received: April 08, 2018 | Published: June II, 2018

\section{Introduction}

Mange is one of the contagious canine skin diseases which continue to pose problems for dog lovers and veterinarians. Various mange mites which include Demodex and Sarcoptes causing demodicosis and scabies, respectively, and cause skin problems have already been isolated from the dogs. ${ }^{1}$ Demodex canis, also called as demodectic mange or red mange or follicular mange, is a normal inhabitant of young dog's skin, especially the short-haired breeds, and is acquired from the dam during nursing. ${ }^{2,3}$ The infection can only be seen in the immunodeficient animals, old dogs and young puppies of about 3 months to a year. Multiplication of mites in hair follicle is aided by suppression or any defect in skin immune system, leading to clinical demodicosis. ${ }^{4}$ Two types of demodicosis are generally seen in dogs. Localized demodicosis starts with one or two hairless spots, especially on muzzle, face, legs and around the eyes, which needs no treatment. Generalized demodicosis is characterized by involving five or more local lesions with patchy areas, erythematous lesions, scales and papules. Affected skin becomes crusted, ulcerated from secondary superficial and deep pyoderma. ${ }^{5}$ Juvenile (localized) stage of demodectic mange requires no treatment in most of the cases and resolves itself whereas generalized stage requires prolonged and life threatening antibiotic treatment. ${ }^{6}$ The mange infestation in dogs has been recorded in different forms in Himachal Pradesh (H.P.) in earlier studies; ${ }^{1}$ however, literature available on prevalence, clinico-haematological alterations and therapeutic management in dogs affected with demodicosis in H.P. is scanty. Present paper describes the prevalence, haematological alterations, clinical signs and therapeutic management of generalized demodicosis in dogs of Himachal Pradesh.

\section{Materials and methods}

Seventy clinical cases of dermatitis were presented to the Teaching Veterinary Clinical of CSKHPKV, Palampur, and were selected in the present study; skin scrapings were collected from all infected dogs. Dogs were of various breeds, in age groups between 1 month to 18 years. Symptoms of severe itching, alopecia, hyper pigmentation, scales, lichenification, crusts, pododemodicosis and keratinization were present in various dogs at the time of examination (Figure 1-5). Information about age, breed and sex was also recorded. Fifteen cases were diagnosed as generalized demodicosis based on signalment, anamnesis and examination of skin scrapings; skin swabs from dogs affected with generalized demodicosis were collected. Alopecia and lesions in localized demodicosis were restricted mainly to all legs.

Deep skin scraping samples were collected with proper sample collection technique from three different areas/lesions of the body for microscopic examination (40X) by using a No. 10 blunt scalpel blade in $10 \%$ potassium hydroxide $(\mathrm{KOH})$ solution. ${ }^{7}$ Pyodermal lesion samples collected in transported medium were used for the bacteriological culture. ${ }^{8}$ Two $\mathrm{ml}$ of blood sample was collected in EDTA $(1.5 \mathrm{mg} / \mathrm{ml})$ tube from six healthy and fifteen demodicosisaffected dogs for complete blood count studies. Packed cell volume $(\mathrm{PCV})$, haemoglobin $(\mathrm{Hb})$, total leucocyte count (TLC), total erythrocyte count (TEC) and differential count were measured by standard methods. The owner was advised to bath the infected dog with benzyl peroxide shampoo applied externally at weekly interval for three to five times, along with Inj. Ivermectin, $1 \mathrm{ml} / 20 \mathrm{~kg}$ body weight, and Amitraz rinses, $3 \mathrm{ml} /$ liter of water, both given at weekly interval for three weeks. Tablets Cefpodoxime, $5 \mathrm{mg} / \mathrm{kg}$, were also given once daily for 10 days to treat concurrent bacterial infection. Supportive nutritional therapy and immune stimulator, $5 \mathrm{ml}$ orally two times daily for one month, were also given along with adequate nutrition during the treatment period. Treatment was continued until complete recovery of the animal. Two consecutive negative skin scrapings after treatment were considered as recovery from Demodex, which was in agreement with findings of the previous studies. ${ }^{4}$ 


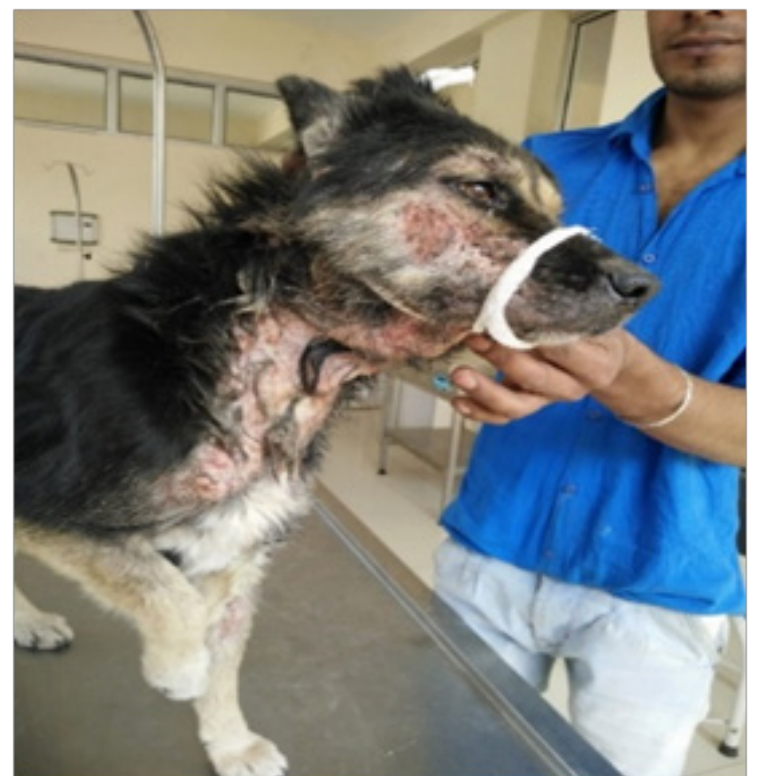

Figure I Mongrel dog showing lesions of alopecia and papular dermatitis in demodectic mange.

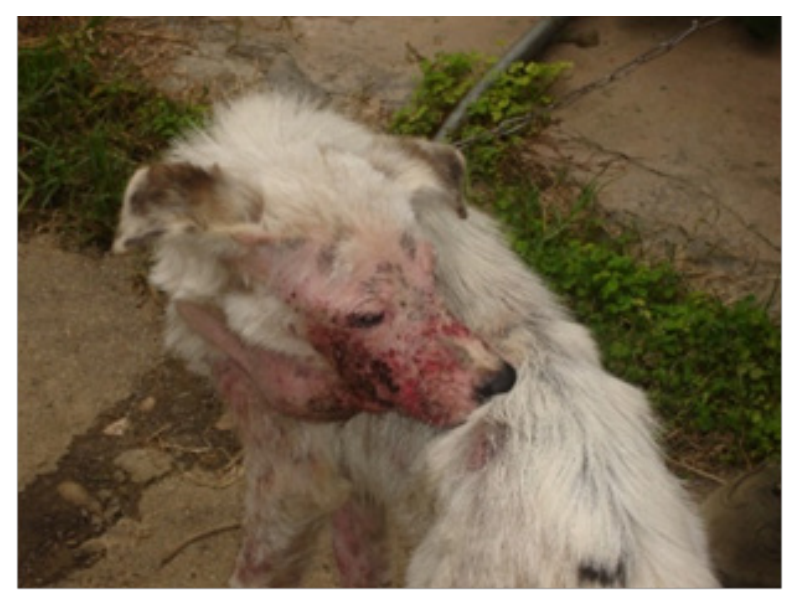

Figure 2 Pomeranian dog showing lesions of alopecia on face, limbs \& trunk.

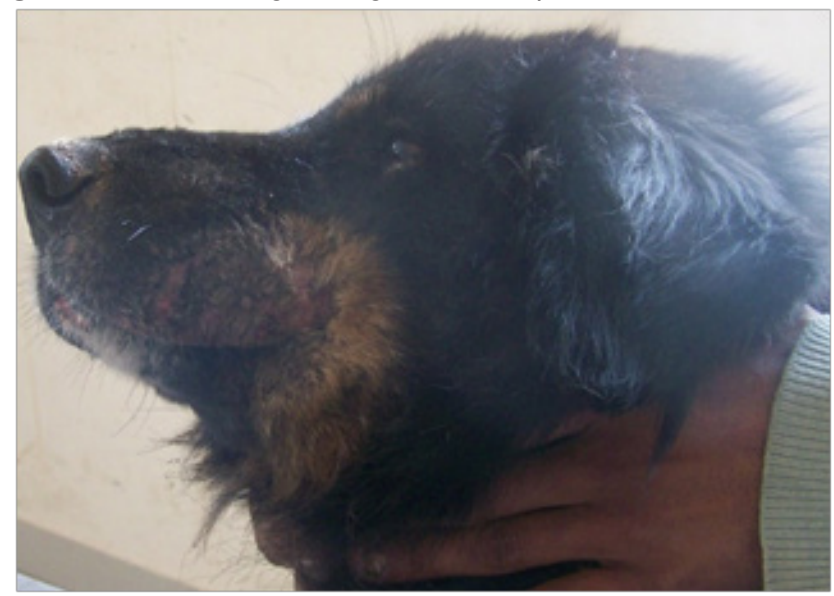

Figure 3 Gaddi dog showing lesions of localized demodectic mange in mouth.

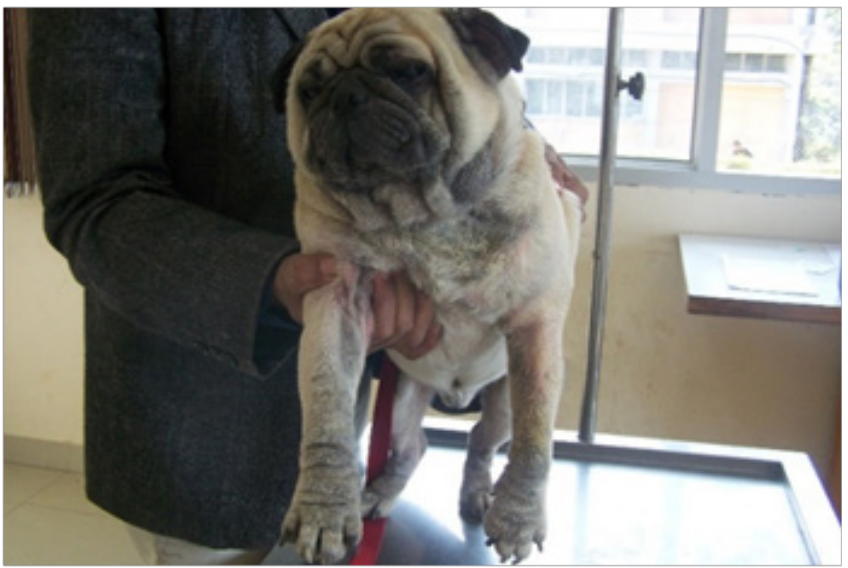

Figure 4 Fore limbs affected and hyper pigmentation of skin in chronic demodicosis.

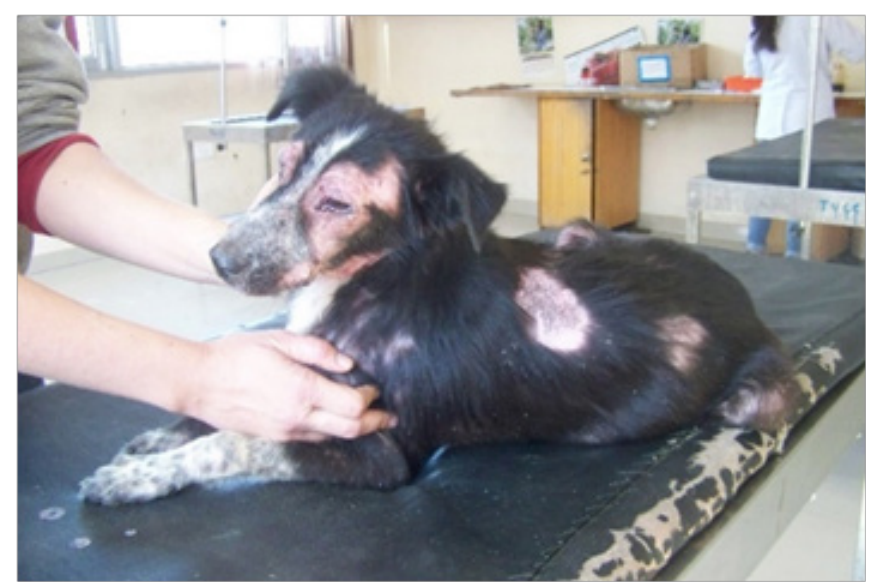

Figure 5 Periorbital area affected by demodectic mange.

\section{Results and discussion}

The occurrence of the species of Demodex has been reported from different parts of the world, including India. Examination of skin scrapings from 70 dogs ( 55 males and 15 females) in this study revealed the presence of Demodex mites in 22 dogs (31.42\%). Out of twenty-two dogs, seven $(31.82 \%)$ had localized demodicosis and fifteen dogs $(68.18 \%)$ were affected with generalized demodicosis (Table 1). Four of the dogs had concurrent Staphylococcus spp. infection. These observations agree with those of Bindari et al., ${ }^{9}$ who reported the prevalence of Demodex around 70\% in Kathmandu Valley of Nepal and with observations of Sarma et al. ${ }^{10}$ who reported 52\% Demodex prevalence among the cases of dermatological disorders. All the animals were heavily infected and microscopic examination of deep skin scrapings revealed the presence of a cigar shaped Demodex spp. (Figure 6). Based on the dermatological findings and diagnostic tests, the dogs were diagnosed with generalized demodicosis and bacterial infection. It has been shown that increased numbers $(>3)$ of mites is an evidence of clinical demodicosis. ${ }^{4}$ The age-wise prevalence of demodicosis in dogs revealed highest prevalence of generalized demodicosis in dogs aged up to 1 year $(36.36 \%)$ followed by 1 to 3 years $(31.82 \%)$ and with the lowest occurrence in dogs aged $>5$ year (13.64\%) (Table 2). These recordings agree with those of Sakina 
\& Mandial ${ }^{1}$ who reported prevalence of $45.71 \%$ demodectic mange in dogs at the age of less than 6 months. Similarly, Kumari et al., ${ }^{11}$ reported prevalence of $70 \%$ demodicosis in less than 2-year dogs, followed by $20 \%$ in 2 to 4 years and with the lowest occurrence of $10 \%$ in dogs aged $>4$ years. Mites being sebophilic led to higher incidence of demodicosis in the younger age group of dogs, which might be due to more stimulation of sebaceous glands during puberty. ${ }^{12}$

Table I Etiology for dermatological affections in dogs

\begin{tabular}{lll}
\hline $\begin{array}{l}\text { Total no. of Dogs with } \\
\text { skin problems }\end{array}$ & $\begin{array}{l}\text { No of dogs having } \\
\text { demodicosis }\end{array}$ & Percentage (\%) \\
\hline 70 & 22 & 31.42 \\
\hline
\end{tabular}

Table 2 Age wise occurrence of demodicosis

\begin{tabular}{llll}
\hline S. no. & Age groups & $\begin{array}{l}\text { No of dogs having } \\
\text { demodicosis }\end{array}$ & Percentage \\
\hline 1 & $0-1 \mathrm{yr}$ & 8 & 36.36 \\
2 & $1-3 \mathrm{yr}$ & 7 & 31.82 \\
3 & $3-5 \mathrm{yr}$ & 4 & 18.18 \\
4 & $>5 \mathrm{yr}$ & 3 & 13.64 \\
& Total & 22 & 100
\end{tabular}

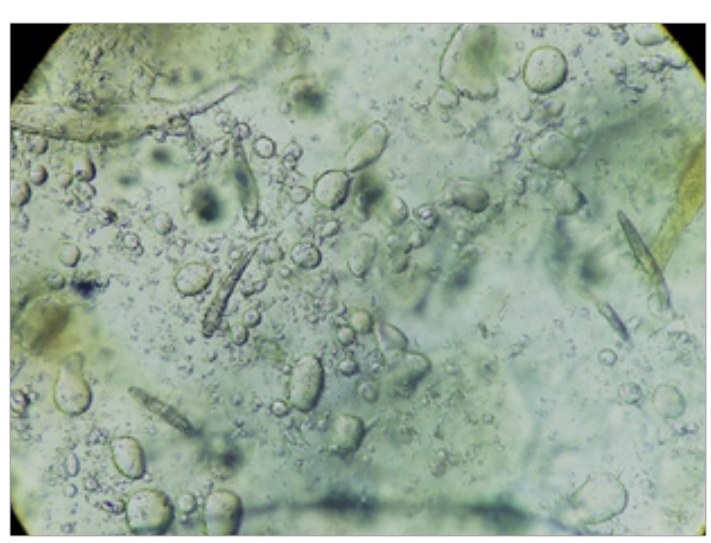

Figure 6 Immature and adult forms of Demodex spp.

In the present study, demodicosis was found significantly $(\mathrm{p}<0.05)$ higher in male $(81.82 \%)$ than female $(18.18 \%)$ dogs (Table 3$)$. These findings are well supported by Chen et al., ${ }^{13}$ and this genderwise discrimination might be attributable to the fact that higher number of male dogs (55) was present in this study. In the present study, breed-wise prevalence of demodicosis was found to be higher in Nondescript/mongrel (36.36\%), followed by Pomeranian, Labrador Retriever and Gaddi (18.18\%), and then followed by German Shepherd, Pug and Boxer (4.55\%) (Table 4). The earlier studies indicated that pure breeds are more susceptible to the disease than crossbreeds, ${ }^{14}$ which was not found in this study. The poor body condition of mongrel/crossbred might have resulted in change of micro-environment of skin, making it more susceptible to multiplication of mites. The next highest occurrence in Pomeranian and Gaddi dogs might be explained by the fact that long-haired dogs pick up dust faster, thus increasing susceptibility to infection. The dogs suffering from generalized demodicosis revealed a wide variety of clinical manifestations (Figure 1-5). Clinical evaluation of fifteen dogs with generalized demodicosis revealed symptoms of alopecia, pruritus, hyperpigmentation and crust formation and these findings were in accordance with the previous study. ${ }^{11}$ The signs associated with the condition are attributable to irritation and inflammatory reaction caused by mites in the hair follicles resulting in damage of the epidermal cells and exudation produced by secondary bacterial and fungal infection. ${ }^{15}$ The pedal pinna reflex was also noted in $73 \%$ (11 out of 15) of dogs. In the present study, lesions were distributed in more than five localized areas to indicate that the dogs were suffering from generalized demodicosis. ${ }^{16}$ The lesion distribution in the study was almost similar to that shown by earlier researchers; ${ }^{: 17}$ although, exact cause of variation of mite infestation in different parts of dog's body remained unclear. The mean haematology values from both groups are given in Table 5. Blood values in normal healthy dogs were within the reference range. Demodectic dogs had decreased average haemoglobin of $10.85 \pm 0.33 \mathrm{~g} / \mathrm{dl}(8.4$ to $12.6 \mathrm{~g} / \mathrm{dl})$ and mean PCV levels was $37.56 \pm 1.81 \%,(26-48 \%)$. TEC varied from $4.68 \times 10^{6}$ to $5.81 \times 10^{6} \%$ cumm with average $5.04 \pm 0.11 \times 10^{6} /$ cumm. In Demodex infection, no observable difference was recorded in packed cell volume, while TEC and haemoglobin levels were decreased, which is in accordance with the findings of Solanki \& Hasnani. ${ }^{18}$ Decreased haemoglobin and TEC is indicative of anaemia and deteriorated conditions of the affected dogs, leading to decreased food intake, systemic illness, toxaemia and septicaemia caused by the Demodex as well as concurrent bacterial infection. ${ }^{19} \mathrm{~A}$ highly significant increase in mean total leucocyte count $\left(15.31 \pm 1.92 \times 10^{3} /\right.$ cumm $)$, mean neutrophil count $\left(71.80 \pm 0.54 \times 10^{3 /}\right.$ cumm $)$, mean eosinophil count $\left(2.38 \pm 0.29 \times 10^{3} / \mathrm{cumm}\right)$, and reduced mean lymphocytes $\left(23.60 \pm 0.65 \times 10^{3} / \mathrm{cumm}\right)$ were found in this study. Increased leucocytosis findings were in association with Reddy et al., ${ }^{19}$ who reported higher leucocyte count in their studies. Neutrophilia, lymphopaenia and eosinophilia in infected animals were in agreement with the studies of Janus et al., ${ }^{18}$ Leucocytosis and eosinophilia found in affected animals could be due to a prolonged antigenic stimulus and hypersensitivity reaction to persistence of Demodex in tissues. ${ }^{20}$

Table 3 Gender-wise occurrence of demodicosis

\begin{tabular}{lll}
\hline Gender affected & $\begin{array}{l}\text { No of dogs having } \\
\text { demodicosis }\end{array}$ & Percentage \\
\hline Male & 18 & 81.82 \\
Female & 4 & 18.18 \\
\hline
\end{tabular}

Table 4 Breed-wise occurrence of demodicosis

\begin{tabular}{llll}
\hline S. no. & Breed of the dog & $\begin{array}{l}\text { No of dogs } \\
\text { having } \\
\text { demodicosis }\end{array}$ & Percentage \\
\hline I & Pomeranian & 4 & 18.18 \\
2 & German Shepherd & 1 & 4.55 \\
3 & Labrador & 4 & 18.18 \\
4 & $\begin{array}{l}\text { Non-descript/mongrel/ } \\
\text { crossbred }\end{array}$ & 8 & 36.36 \\
5 & Pug & 1 & 4.55 \\
6 & Gaddi & 4 & 18.18 \\
& Total & 22 & 100 \\
\hline
\end{tabular}


Table 5 Mean haematological values of healthy and demodicosis dogs (Mean \pm SE)

\begin{tabular}{llll}
\hline Parameters & $\begin{array}{l}\text { Normal group } \\
\text { Mean } \pm \text { SE }(\mathrm{n=6})\end{array}$ & $\begin{array}{l}\text { Dogs with demodicosis } \\
\text { Mean } \pm \text { SE }(\mathbf{n = 1 5})\end{array}$ & P value \\
\hline $\mathrm{Hb}(\mathrm{g} / \mathrm{dl})$ & $13.73 \pm 0.54$ & $10.85 \pm 0.33^{*}$ & 0 \\
$\mathrm{PCV}(\%)$ & $41.67 \pm 1.22$ & $37.56 \pm 1.8 \mathrm{INS}$ & 0.07 \\
TEC $\left(10^{6} / \mathrm{mm}^{3}\right)$ & $6.20 \pm 0.25$ & $5.04 \pm 0.1 \mathrm{I}^{*}$ & 0 \\
TLC $\left(10^{3} / \mathrm{mm}^{3}\right)$ & $9.92 \pm 0.28$ & $15.31 \pm 1.92^{*}$ & 0.01 \\
Neutrophils $\left(10^{3} / \mathrm{mm}^{3}\right)$ & $70.67 \pm 0.37$ & $71.80 \pm 0.54^{*}$ & 0.01 \\
Lymphocytes $\left(10^{3} / \mathrm{mm}^{3}\right)$ & $25.67 \pm 0.73$ & $23.60 \pm 0.65^{*}$ & 0.01 \\
Monocytes $\left(10^{3} / \mathrm{mm}^{3}\right)$ & $1.17 \pm 0.34$ & $1.13 \pm 0.15 \mathrm{NS}$ & 0.86 \\
Eosinophils $\left(10^{3} / \mathrm{mm}^{3}\right)$ & $1.33 \pm 0.37$ & $2.38 \pm 0.29^{*}$ & 0.04 \\
Basophils $\left(10^{3} / \mathrm{mm}^{3}\right)$ & $1.17 \pm 0.34$ & $1.15 \pm 0.18$ & 0.97 \\
\hline
\end{tabular}

NS non-significant $(P>0.05)$

$* \mathrm{P}<0.05$ (significant).

Following three-week treatment, fifteen cases responded, and skin scrapings were found negative for Demodex. Clinical signs disappeared in these cases after the $28^{\text {th }}$ day of therapy. However, seven cases were still found positive for the mite. Benzoyl peroxide shampoo possesses keratolytic and follicular flushing activity and hence is recommended for the treatment of demodicosis. ${ }^{21}$ Amitraz along with antibiotic treatment is effective for demodectic mange. ${ }^{22,23}$ Application of Amitraz should be preceded by a shampoo such as benzoyl peroxide applied several hours before to remove crust, debris, and bacteria; the dipping should be continued for at least two treatments after negative scrapings have been obtained. ${ }^{24,25}$ Ivermectin given orally for generalized demodicosis leads to paralysis and death of mites. Demodicosis in dogs cause immune suppression; ${ }^{4}$ to boost immunity, immune boosters have been given to the dogs, which indicated good results. All the presented cases showed good response to the treatment.

\section{Conclusion}

The prevalence of generalized demodicosis accounted for 31.42 per cent among various dermatological disorders. The age-wise prevalence showed highest occurrence in dogs aged up to 1 year, with male predominance. The breed-wise occurrence showed highest prevalence in mongrel followed by Pomeranian, Labrador Retriever and Gaddi. Corrugation of skin, alopecia, crusts and pruritus were the most observed clinical signs. It is extremely important to critically evaluate dermatological disease during each examination with the proper baseline diagnostic testing. It is also essential to understand the risks, benefits and possible side effects of all therapies administered when creating a long-term treatment.

\section{Acknowledgements}

We are thankful to Dean, COVAS

\section{Conflict of interest}

The author declares that they have no conflict of interest.

\section{References}

1. Sakina A, Mandial RK. Prevalence and clinical observations of mange in dogs. Vet Pract. 2011;12(2):248-50.
2. Sivajothi S, Reddy BS, Rayulu VC. Demodicosis caused by Demodex canis and Demodex cornei in dogs. J Parasit Dis. 2015;39(4):673-676.

3. Greve JH, Gaafar SM. Natural transmission of Demodex canis in dogs. $J$ Am Vet Med Assoc. 1966;148:1043-1045.

4. Mueller RS, Bensignor E, Ferrer L, et al. Treatment of demodicosis in dogs: 2011 clinical practice Guidelines. Vet Dermato. 2012;23(2):86-96.

5. Alice MJ. Canine demodicosis: Serious disease requires aggressive therapy. DVM 360 Magazine; 2006.

6. Fourie LJ, Kok DJ, Du Plessis A, Rugg D. Efficacy of a novel formulation of metaflumizone plus amitraz for the treatment of demodectic mange in dogs. Vet Parasitol. 2007;150(3):268-274.

7. Soulsby EJL. Helminths arthropods and protozoa of domestic animals. $7^{\text {th }}$ edn. UK: London; 1982. p. 482-486.

8. Bauer AW, Kirby WMM, Sherris JC, et al. Antibiotic susceptibility testing by a standardized single disc method. Am J Clin Pathol. 1966;45(4):493496.

9. Bindari YR, Shrestha S, Shrestha MN. Prevalence of mange infestation in canines of Kathmandu valley. Int J Vet Sc. 2012;1(1):21-25.

10. Sarma K, Mondal DB, Saravana M, et al. Incidence of dermatological disorders and its therapeutic management in canines. Intas Polivet. 2013;14(2):186-192.

11. Kumari D, Syaama Sundar BN, Rao, VV, et al. Clinical signs and epidemiological and in canine demodicosis. Int $J$ Sci Env Tech. 2017;6(1):854-860.

12. Schwartzman RM, Orkin RM. A comparative study of skin disease of dogs and man. Charles Thomas- Pub: USA; 1962.

13. Chen Y, Lin R Zhou D, et al. Prevalence of demodex infection in pet dogs in Southern China. Afr J Microbiol Res. 2012;6:1279-1282.

14. Solanki JB, Hasnani JJ, Patel DM, et al. Canine demodicosis in Anand. $J$ Vet Parasitol. 2007;21(1):79-80.

15. Mueller GH, Krik RW Scott DW. Small Animal Dermatology. $3^{\text {rd }}$ edn. W B Saunders Company: Philadelphia; 1989.

16. Scott DW, Miller WH, Griffin CE. Muller and Kirk's Small Animal Dermatology. $5^{\text {th }}$ edn. Saunders: Philadelphia; 1995. p. 882-883.

17. Yogeshpriya S, Sivakumar M, Selvaraj P, et al. Efficacy of amitraz plus miconazole for the treatment of juvenile generalized demodicosis 
associated with dermatophytosis in a Pug. J Entomol Zool Stud. 2017;5(5):1698-1700.

18. Solanki JB, Hasnani JJ. Clinico-prevalence of canine demodicosis in Gujarat. Indian J Field Vet. 2006;1(3):11-13.

19. Reddy B, Kumari S, Nalini K, et al. Haemato-biochemical findings and thyroxin levels in canine demodicosis. Comp Clin Pathol. 2015;24(2):287290.

20. Dhume GV, Sharode DB, Dakshinkar NP, et al. Haematobiochemical investigation in canine demodicosis. The Blue cross book. 2002;19(3):1617.

21. Scott DW, Miller WH, Griffin CE. Dermatologic therapy. Mueller and Kirk's Small Animal Dermatology. 6 ${ }^{\text {th }}$ edn. Saunders: Philadelphia; 2001.
22. Mueller RS. An update on the therapy of Canine Demodicosis. Compend Contin Educ Vet. 2012;34(4);E1-4.

23. Tarallo VD, Lia RP, Sasanelli M, et al. Efficacy of amitraz plus metaflumizone for the treatment of canine demodicosis associated with Malassezia pachydermatis. Parasit Vectors. 2009;2(1):13.

24. Verde M. Canine Demodicosis: Treatment Protocol. Proceeding of the NAVC North American Veterinary Conference. Orlando: Florida; 2005. $299 \mathrm{p}$.

25. Sarkar P, Chakraborti A, Ghosh D. Studies on hematology and serum biochemistry profile in canine demodicosis. Indian Vet J. 2009;86:676678. 